\title{
NUEVOS TEONIMOS HISPANOS. ADDENDA ET CORRIGENDA V
}

J. M. BLÁZQUEZ

La lista de teónimos hispanos se incrementa considerablemente todos los años. Acabamos de publicar la lista con correcciones debida a M. L. Albertos (1), pero hay que añadir a esta lista algunos de última hora.

1. En Alcaçova do Castelo de Mértola, J. Pulido Valiente, J. C. Almeida Oliveira y M. Pereira dos Santos (2), han dado a conocer un ara dedicada a Deae Sactae: DEAE / SANCT/AE VOT/UM ANI/MO LIBE/NS SOLVI/T [C(aius) VAL(erius)]/ RVFVS/CAEPIO.

Este ara debe estar dedicada a Ataecina (3), asimilada a Proserpina por los epítetos que en otras inscripciones acompañan a esta diosa, de carácter funerario.

2. J. Candeias Silva (4) publica un ara de Mouriscas (Abrante), que dice: M(arcus?) / OMELI(us?) / CATRO TANG/INI F(ilius), ALVA V(otum) A(nimo) L(ibens) S(olvit).

Al parecer el ara está dedicada al dios Alva.

3. J. d'Encarnação (5) ha recogido varios fragmentos de inscripciones en número de 9 dedicadas al dios lusitano Endovelico, el dios hispano que contó con más epígrafes a él consagrados en Hispania.

4. En Santa Eufémia (Pinhel) (6), en el conventus scallabitanus, se ha recogido un ara dedicada a un dios indígena, del que sólo se conservan dos letras R[?] C[?], cuya lectura es la siguiente: C ASABVVS/ [T]VRRILI F(ilius) / V(otum). S(olvit). L(ibens. M(erito) / R[?]. C[?].

(1) Blázquez, J. M.: Historia de España. España Romana, Espasa Calpe, Madrid, 1982, 309 ss.; idem, Primitivas religiones ibéricas, II. Religiones prerromanas, Madrid, 1983, 477 ss. La misma lista, puesta al día, se publica en: idem, "Einheimische Religionen Hispaniens in der römischen Kaiserzeit», ANRW, II, Berlín, 1986, 165 y ss.

(2) "Ara votiva de Mértola (Conventus pacensis)", Ficheiro Epigráfico, 1, 1982, 3 ss.

(3) Blázquez, J. M.: Primitivas religiones ibéricas, 284 ss.

(4) "Inscrição votiva de Mouriscas (Abrantes) (Conventus Scallabitanus)", Ficheiro Epigráfico, 1, 6 ss.

(5) "Textos fragmentados en honore de Endovelico", Ficheiro Epigráfico, 3, 1982, 3 ss.

(6) López Tomé, M. L.: "Uma inscrição votiva de Santa Eufemia (Pinhel) (C. Scallabitanus)", Ficheiro Epigráfico, 5, 1983, 6 ss. 
6. En Ouguela, Campo Maior (7), en el conventus pacensis, se ha encontrado una segunda ara consagrada a Ataecina, en la que se lee:

Q... P... D(eae). S(anctae). [T(urubrigensi)]/V(otum). Q(uod). F(ecit). A(nimo) L(ibens) [P(osuit)] /... E(x). M(onitu).

Ataecina es la segunda diosa hispana con más epígrafes a ella dedicados.

7. En el mismo conventus scallabitanus en Penamacor (8), ha aparecido un ara consagrada a Deo Duangeio, que dice:

CATVRO / TUREIV DEO/ DVANGEIO V(otum) S(olvit).

En esta inscripción por sincretismo se añade la palabra Deo (9), al teónimo (fig. 1).

8. En Sabugal (10), también en el conventus scallabitanus, se ha hallado un ara erigida en honor de una diosa bien conocida en Hispania, Arentia (11) (fig. 2).

El epígrafe es el siguiente:

ARENTI/AE. EQUO/TVLLAICEN/SI. NICER/ARCONIS (filius) / ...

9. En el mismo conventus scallabitanus (12) (fig. 3), se han encontrado dos inscripciones en honor de Laepus, en Pousafoles, Sabugal. En ellas, se lee:

TANGINV/S. L(ucii) BOVTI(i) (filius) / (LAEPO. A(nimo) L(ibens). V(otum). S(olvit) LAIIPO/. V(otum). S(olvit). BASSV/S VIRIA/TI. F(ilius)

Al parecer, hay que leer el nombre de este dios, Laepo, y no Caepo, como se había leído hasta el momento presente.

10. En Ercavica, Cuenca, en una piedra se escribió el nombre de un dios indígena: Aribelo (13).

11. En la Sierra de San Pedro, en El Gaitán, Cáceres, se ha descubierto un ara consagrada a Nabia, que dice:

$$
\begin{gathered}
\text { A(ugustae) NABIAE / VICTOR / SEMPR(onius) S(acrum) / } \\
\text { A(nimo) L(ibens) V(otum) S(olvit) }
\end{gathered}
$$

Con motivo de publicar este ara J. L. Melena (14) cataloga las 14 inscripciones dedicadas a Nabia, aparecidas en la Península Ibérica, a las que añade otras dos (Mapa 1).

(7) Dias Diogo, A. M.: "Ara votiva de Ougela, Campo Maior (Conventus Pacensis)", Ficheiro Epigráfico, $8,1984,8$ ss.

(8) Curado, F. P.: “Ara a Duangesius, de Penamacor (Conventus Scallabitanus)", Ficheiro Epigráfico, 7, 1984,3 ss.

(9) Lambino, S.: "Les cultes indigenes en Espagne sous Trajan et Hadrien», Les empereurs romains d'Espagne, París, 1965, 223 ss.

(10) Curado, F. P.: “Monumento votivo a Arentia, de Sabugal (Conventus Scallabitanus)", Ficheiro Epigráfico, 7, 6 ss.

(11) Blázquez, J. M.: Primitivas religiones ibéricas, 477 ss.

(12) Curado, F. P.: "Aras a Laepus procedentes de Ponsafoles, Sabugal (Conventus Scallabitanus)", Ficheiro Epigráfico, 7, 8 ss.

(13) Rodríguez Colmenero, A.: “Cuenca romana. Contribución al estudio Epigráfico II", Lucentum, II, 1983,229 ss.

(14) "Un ara votiva romana de El Gaitán, Cáceres", Veleia, 1, 1984, 1 ss. 


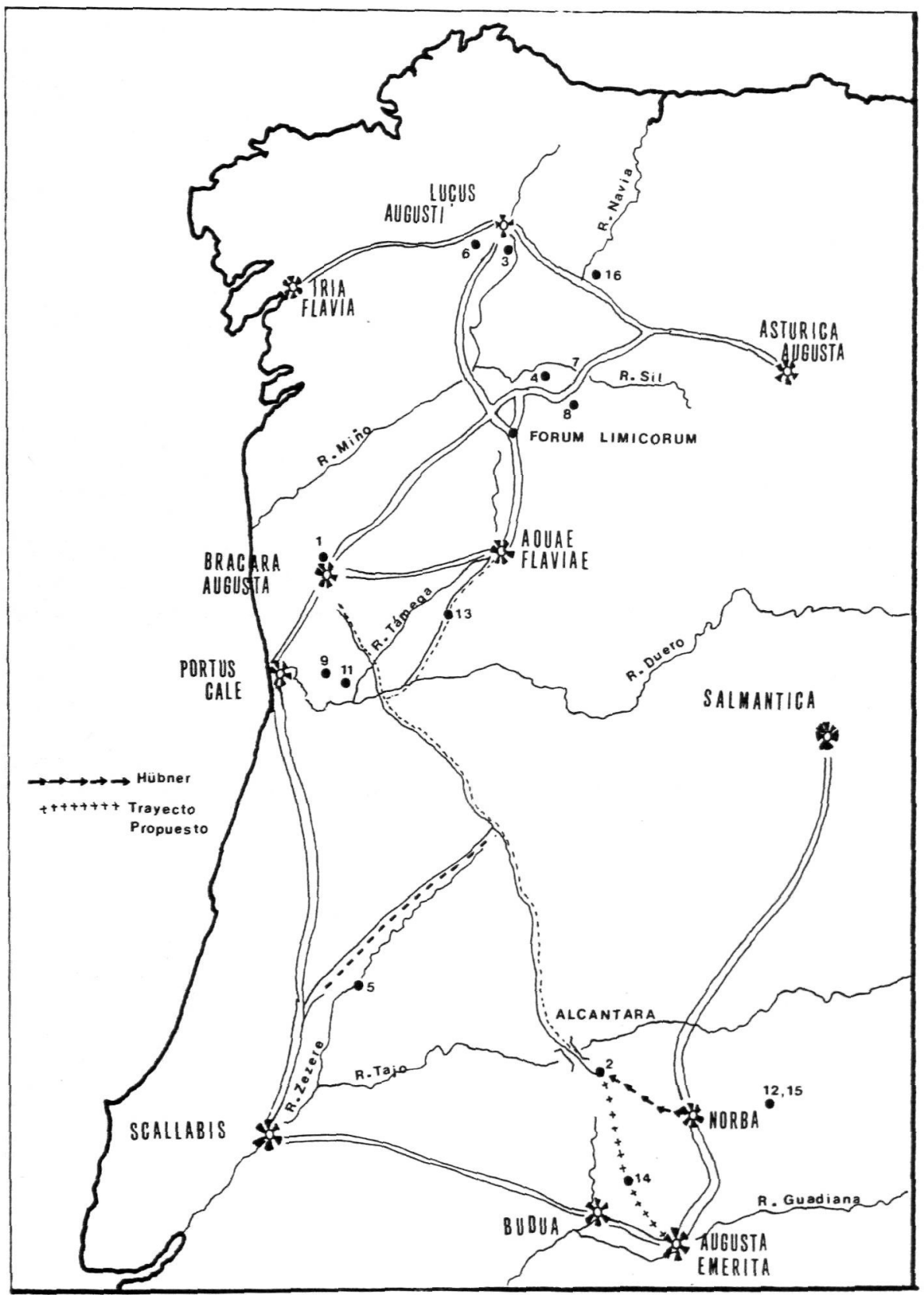

MAPA 1-Distribución del teónimo Navia. Según Melena. 
Corrige la lectura propuesta de la diosa Abisai, de Trujillo, también en Cáceres, en la que propone leer:

.... VRVS. T/AN(cini). L(ibertus) / NAVI[e] S(acrum) A(nimo) L(ibens) / ARAM. P/OSUIT ET / VOT(um). SOL(vit)

Recoge, igualmente, el autor de la inscripción de San Román de Cervantes, Lugo, que dice:

[Nabi]AE / [Sacrum] M/ C. VALERIVS / CARVS / MILES L(egionis). X. G(eminae) / V(otum). S(olvit). L(ibens). M(erito),

con lo que serían 16 en total las inscripciones en honor de la diosa Nabia, que sería de este modo la tercera deidad del panteón hispano en importancia, a juzgar por la extensión y número de los epígrafes a ella dedicados.

Melena no sigue la opinión de P. Le Roux, A. Tranoy y de nosotros sobre la oscilación del teónimo Nabia en el conventus de Braga y Navia en el de Lugo, sino que interpreta esta oscilación entre la $b$ y la $v$ en posición interválica, que comienza en latín con la edad imperial. Siguiendo a A. Carnoy, se inclina J. L. Melena a que la forma primitiva era Nabia.

Estudia también este autor a la diosa Nabia dentro de la religión lusitana. Recoge los epítetos o adjetivaciones cultuales, con que se presenta en las inscripciones la diosa: Elaesuaraega, Arconiunieca, Sesmaca, para deducir que la epíclesis gentilicia de las formaciones en -Ko no implica la existencia de una pluralidad de diosas, sino de advocaciones epicóricas, que encuentran paralelos en todas las religiones y culturas.

En el conocido monumento de Tongoe/nabiago de Braga, se tendría la vinculación de la diosa Nabia con un dios acuático, Tongus, vinculación similar a la que se atestigua en el ara de Trujillo, en la que Nabia aparece junto con el dios acuático Salamus. El lugar de origen de esta diosa sería Bracara. Sobre la significación del teónimo Nabia, J. L. Melena propone una nueva etimología, pues descarta su sentido acuático, generalmente admitido por los investigadores, que se han ocupado de la diosa, pues difícilmente puede relacionarse con nau-s. Propone este autor que, como en indoeuropeo, son contadas las formas con $b$, se estaría ante un caso de sonorización secundaria, en posición intervocálica, de una $p$ originaria. Seguramente se relacionaría más probablemente con el griego nape, término con el que se designa a los valles selvosos ya desde Homero (II 8. 558), lo que indicaría la existencia de un extenso sustrato lingüístico anterior a la indoeuropeización de la cuenca del Mediterráneo. De esta etimología se deduce que Nabia sería una diosa indígena de los bosques, de los montes, y de los valles selvosos, una Diana indígena, lo que confirmaría la afirmación de Martin Dumiense en su De correctione rusticorum 16, que habla de que los rústicos adoraban «en las selvas a las Dianas». J. L. Melena pasa a continuación a examinar la dispersión geográfica del culto a Nabia, formando cuatro grupos con las inscripciones: el lucense con 2 inscripciones, el'orensano con 4; el bracaraugustano con 5, y el cacereño con 4. El área de dispersión de su culto a partir del conventus bracaraugustanus, indica que se difundió siguiendo unas vías bien definidas:

a) Por el Norte, posiblemente por Aquae Flaviae y Forum Limicorum, para escindirse hacia Lucus Augusti y Asturica Augusta. 


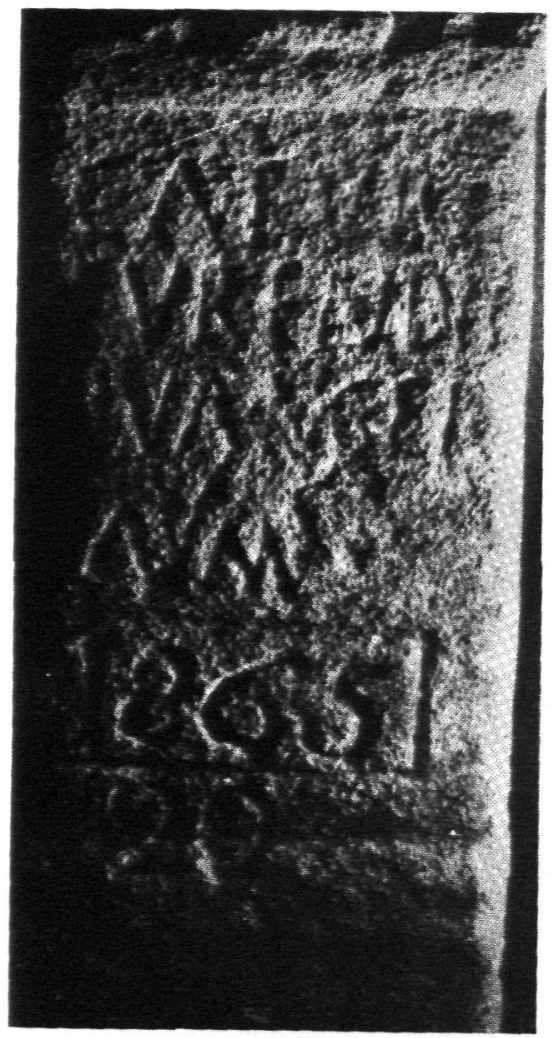

FIG. 1.-Ara de Duangeius

(según F. Patricio Curado).

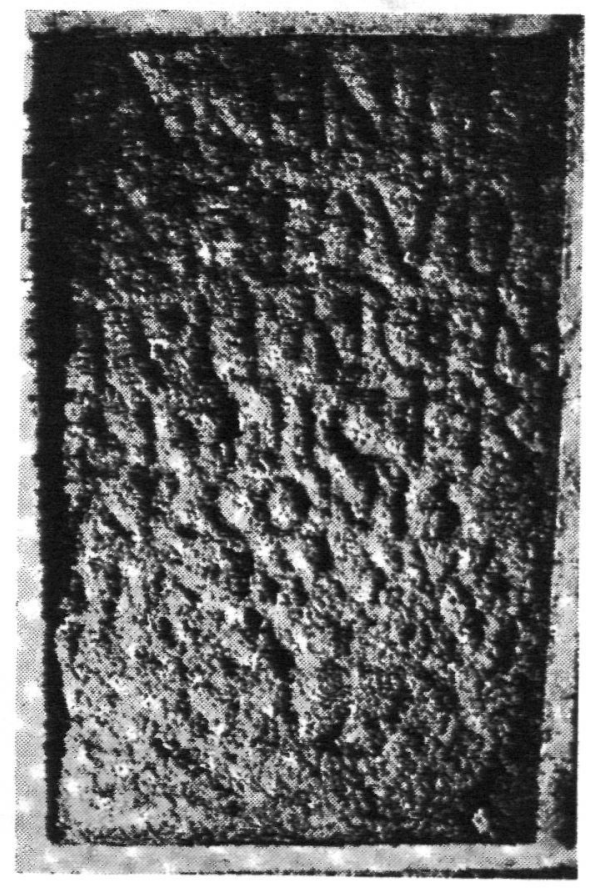




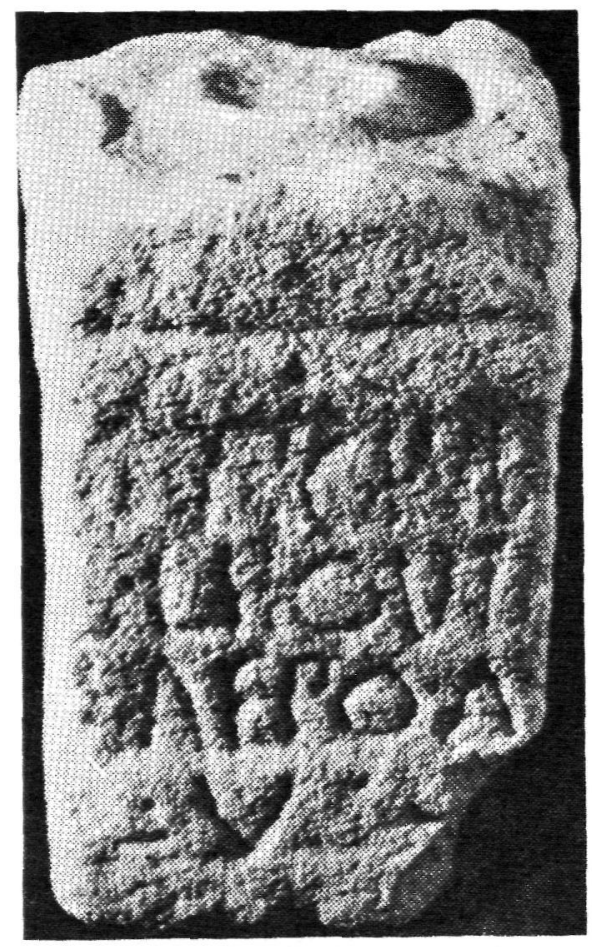

FIG. 3.-Ara de Laepus

(según F. Patricio Curado).

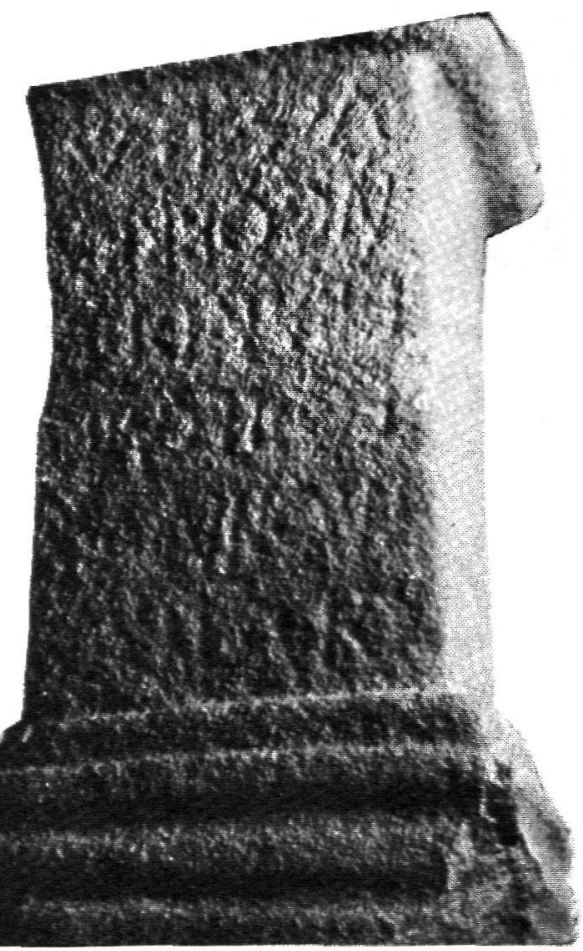


b) Hacia el sur siguiendo la vía hacia Augusta Emerita. La inscripción de El Gaitán debe vincularse con la calzada de Augusta Emerita hacia el NO. de la Península Ibérica.

11. En Bienvenida, Badajoz (15), se ha recogido un epígrafe a la diosa Ataecina, que dice:

DOMINA / [A]TTAEGINA / [T $\left.T_{\dot{c}}\right]$ VRVBRIGA[E]... TIRIBVS. SVIS / [RE]COLLECTIS.

12. X. Pereira Menaut y C. A. Ferreira de Almeida (16) proponen una nueva lectura a la inscripción de Vilar de Perdices, Montealegre en Portugal, que es la siguiente:

Cuya lectura es:

\author{
ALLIVS REBVRRI ROGO DEV(M) \\ ADIVTOREM \\ IN AC (sic) CONDVCTA CONSERVANDA \\ QU(S)QIS (sic) IN AC (sic) CONDVCTA \\ $\mathrm{P}($ OSSESSIONEM) MICI (sic) AV'T \\ MEIS \\ INVOLAVERIT SI R(EMPS) \\ QVAECVNQVAE (sic) RES AT MII \\ ITT A V S SIL SIQVIT EA RES V S L V F \\ DANCEROI
}

Señalan ambos autores, que, como en el caso de la inscripción dedicada a la Dea Ataecina Turibrigensis Proserpina, CIL II 462, hallada en Emerita, se trata de una invocación a una deidad para que impida o repare el daño causado por otra persona. Ambas dedicatorias tienen un cierto carácter de defixio. El dedicante pide al dios contra las personas que intentan usurpar unas tierras. Este documento es el primero conocido en el NO. hispano sobre la forma de tenencia de tierras, a los comienzos de la romanización antes de la concesión del ius Latii por el emperador Vespasiano a los hispanos. Esta inscripción es un dato importante para comprender el cambio de estructura que se originó en esta región antes de los finales del siglo I. Todo parece indicar que el arrendamiento de las tierras debía ser el régimen habitual entre las poblaciones indígenas en la primera etapa de la romanización. Por alguna expresión empleada piensan estos autores que el arrendamiento sería a largo plazo, y que pasaría a los descendientes.

13. A. Blanco (17) acaba de publicar un exhaustivo estudio sobre los verracos y toros. De la existencia sobre ellos de una veintena de inscripciones deduce su carácter funerario, así como de la presencia de algunos otros elementos rituales. Su cronología sería ya romana, incluso imperial y llegarían muy probablemente hasta

(15) Esteban Ortega, J.: "Epigrafía sobre la diosa Ataecina en Bienvenida (Badajoz)", Actas de las II Jornadas de Metodología y Didáctica de la Historia (Historia Antigua), Cáceres, 1984, 21 ss.

(16) "A grande inscrição do Penado de Remeseiros, Vilar de Perdices, Montealegre (CIL II, 2476)", Arqueologia, 4, 1981, 142 ss.; Blázquez, J. M.: Primitivas religiones ibéricas, 231, 287, 291

(17) "Museo de los verracos celtibéricos", BRAH, 181, 1984, 1 ss. 
el Bajo Imperio. El uso del verraco sería un fenómeno autóctono, derivado del sacrificio de una res en el funeral del difunto. Descarta la influencia de los 'pueblos del sur en los orígenes de las esculturas de los verracos. En cambio en las esculturas de los toros de pie o sentados del sur, pudieron muy bien inspirarse los creadores de los primeros verracos, extendiéndose entonces o después, a los cerdos.

14. R. Grandel del Brío (18) ha publicado un bello libro dedicado a la biología y a la mitología del lobo ibérico, en el que trata aspectos relacionados con la religión del lobo en la Hispania Antiqua, en Etruria y en Roma, en las mitologías griega, germana y céltica, en la hagiografía cristiana de la Edad Media, en la mitología del País Vasco, etc. El lobo desempeñó un papel importante en la religión de la Hispania Antigua, que hay que rastrear bien y del que apenas se ha estudiado nada.

15. Con el dios Lug (19), se ha relacionado el sacrificio fundacional de tres cadáveres en las murallas de Bilbilis, fechado en el s. I a. C. Uno de ellos acompañado del sacrificio de una garduña, de un cerdo y de una oveja. El segundo, de dos córvidos, con cerámicas a ellos asociadas. Todo lo cual prueba la existencia de sacrificios de fundación entre los celtíberos. Recoge el autor las fuentes literarias que hablan de sacrificios humanos entre los hispanos.

El rito del descarnamiento de los cadáveres, al que alude Silio Itálico y Eliano, lo relaciona M. Salinas con el dios $\mathrm{Lug}$. Recoge este autor los testimonios de la vinculación del cuervo con Lug, la inscripción de Peñalba de Villastar (Teruel), que cita al dios Lug, en la que se representa a un cuervo. Cataloga las inscripciones del dios Lug en Hispania. Compara la inscripción con la de los Lugones, con la de Nimes a Lucubus, o con la de Lugones de Aventicum. Compara también siguiendo a De Vries a los Lugones del ara de Uxama, dedicada por el gremio de los zapateros a las figuras del Mabigony galés Gwydyon y de su hijastro Lleu Llanu Gyffes, que son precisamente zapateros. La cristianización de estos dioses paganos, de los que Lug fue el más importante, serían los mártires cristianos de Soissons, Crispín y Crispiniano, patronos de los zapateros, santos representados en dos tallas barrocas de Santa María de Ledesma (Salamanca). Recoge también M. Salinas en su estudio, la teoría de McCarna, Sjoestad, Le Roux, etc., que relacionan los Lugones con la triada fundamental del panteón celta, o con la costumbre de multiplicar por tres sus divinidades, interpretación avalada por la existencia de tres foci en las aras gallegas de Sinoga, de Otero y de San Vicente de Castillones. Cree M. Salinas que Lug es el dios más importante del panteón celta, y por eso a él se le inmolarían los sacrificios humanos de la muralla de Bilbilis.

Piensa este autor que el rito fundacional de la muralla de Bilbilis, podría hacer referencia a un dios mago, como aparece $\mathrm{Lug}$ en las leyendas irlandesas, de este modo elementos de la magia y de la religión se combinarían en un mismo acto ritual.

(18) El lobo ibérico. Biología y mitología, Madrid, 1984.

(19) Salinas, M.: "El culto al dios celta Lug y la práctica de sacrificios humanos en Celtiberia", Studia Zamorensia, 4, 1983, 304 ss. 
16. M. Salinas (20), con motivo de estudiar la organización social de los vetones, cataloga todas las deidades, casi todas son indígenas, aparecidas entre los vetones, que suman 42, con su correspondiente bibliografía. Dedica un capítulo a examinar la religión indígena en relación con la organización nativa, donde se analizan los dioses indígenas. Recoge las diferentes opiniones emitidas por los investigadores sobre las esculturas llamadas verracos, y propone que "estas esculturas zoomorfas habrán de situarse, en todo caso, en el contexto de las creencias mágicoreligiosas de los pueblos organizados a la manera tribal, probablemente en relación más que con creencias de carácter apotropaico, con ritos de reproducción e incremento de la especie».

17. Jose d'Encarnação (21) ha estudiado recientemente «A religião romana naooficial nas colonias e municipios da Lusitânia durante o Alto Imperio». En este trabajo alude el autor a ciertos cultos indígenas y al sincretismo con las deidades indígenas.

En los alrededores de Aegitania, detecta el autor la pujanza de cultos indígenas, como los Lares Cairieses y Reva Langanitaecus. En Ammaia, se tributó culto a Ocrimira y a Toga Alma. En Mirobriga la palabra deus junto al teónimo Aesculapius demostraría la asimilación de un dios romano a una deidad indígena de nombre desconocido. Al mismo grupo pertenecería el Asclepio Deo de Valentia (CIL II 3726), publicado por G. Pereira Menaut (22).

Concluye S. 'd'Encarnação que en los centros urbanos del interior, donde predominaba la población indígena, los dioses indígenas tuvieron alguna importancia.

18. M. J. Pena (23) analiza el culto a Tutela en Hispania, y la procedencia de los dedicantes de las inscripciones. Agrupando en varios apartados los epígrafes. Hace también un corpus muy útil de todas las inscripciones hispanas, dedicadas a Tutela, que suman 26. Es importante señalar los adjetivos que acompañan a Tutela: Pantheo en Tortosa y deo en Alhama de Aragón y en La Guardia (Jaén). Estas dos últimas son deidades indígenas asimiladas a otra romana.

19. M. Pastor (24) estudia todas las inscripciones conocidas de Silvano, halladas en Hispania, concluyendo, que no gozó su culto de gran predicamento entre las poblaciones indígenas, pero que la existencia de un antiguo culto a los árboles y a los bosques, parece relacionar dicho culto al que se ofrecía a Silvano, produciéndose, quizá, una asimilación o identificación por sincretismo, bien patente en la inscripción de Porcuna (Jaén) al numiní deo sancto Silvano.

20. S. Santamaría (25) estudia el culto a los Lares, tan venerados en Galicia y Lusitania, en el conventus asturum.

(20) La organización tribal de los vettones, Salamanca, 1982.

(21) Memorias de Historia Antigua, 5, 1981, 19 ss.

(21) Inscripciones romanas de Valentia, Valencia, 1972, $24, \mathrm{n}^{\circ} 2$.

(22) "El culto a Tutela en Hispania», Memorias de Historia Antigua, 5, 73 ss.

(24) "El culto al dios Silvano en Hispania: Innovación o sincretismo". Memoria de Historia Antigua, 5, 103 ss.

(25) "El culto a los Lares en el conventus Asturum: la inscripción de Villadecanes", Memoria de Historia Antigua, 5, 125 ss. 
21. En Santibáñez (El Bierzo, León) (26), se ha recogido un nuevo teónimo hispano: Vdumaeo.

22. En El Valle y Tedejo (León) (27), se ha hallado una inscripción dedicada a C[O]S[SVE] / TVE[RAN]/AEO. PA[RA], dedicada por un soldado de nombre Tito Flao, de la Legio VII Gemina, y una segunda a la misma diosa, bien documentada en la Hispania Antigua:

\section{CO [SSVE] / V[D]VNA[EO] / ITILIN[V]E.}

Dedicada a la misma diosa se ha encontrado una tercera inscripción en San Pedro Castañero, también en el Bierzo (28).

23. En Poza de la Sal (Burgos) han sido recogidas nuevas urnas en forma de casa, importantes para conocer las creencias indígenas de esta región sobre la ultratumba (29).

24. J. Mangas (30), con ocasión de estudiar "La difusión de la religión romana en Asturias", alude a algunos dioses indígenas, asimilados a Júpiter, como I.O.M. Candiedo, I.O.M. Andero, I. Ladico, I. Candamo, a los Lares en estrecha relación estos últimos con la cultura castreña; y a varios dioses relacionados con las aguas (Genius Fontis Agineesis, Nymphae Fontis Amevi). Clasifica en cuatro tipos las lápidas funerarias en Asturias.

25. C. Fernández Ochoa (31) recoge todas las dedicatorias que han aparecido en Asturias dedicadas a teónimos indígenas: Barciaeco, Nimmedo Seddiago, Parameco, Tabalieno.

26. E. Rodríguez Almeida (32) ha publicado todas las inscripciones de Avila, entre las que se encuentran varias dedicadas a nombres indígenas: $T o($ goti. $), n^{\circ}{ }^{\circ} 62$; Velico, n. ${ }^{\circ}$ 76-84.

27. F. Calo (33) ha estudiado el simbolismo en la cultura material castreña. Estudia la decoración de la Pedra Formosa de Briteiros y de otras similares. Recoge las diferentes interpretaciones propuestas sobre su significado, generalizándose de que se tratase de monumentos funerarios, de hornos crematorios, o de lugares de culto a las aguas. El autor se inclina por creer que se trata de una especie de sauna.

En segundo lugar F. Calo estudia los llamados guerreros lusitanos, que se levantarían para rendir tributo al guerrero. Recoge las diferentes interpretaciones que se han propuesto sobre ellos, la funeraria, la de que se trataría de imágenes

(26) Mangas, J.: “Nueva inscripción romana de Santibáñez (El Bierzo, León), Memoria de Historia Antigua, 5, 257 ss.

(27) Mangas, J.: “Dos inscripciones romanas inéditas de El Valle y Tedejo (El Bierzo, León)», Memoria de Historia Antigua, 5, 263 ss.

(28) Mangas, J.: “Nueva inscripción de San Pedro Castañero (El Bierzo, León), Memoria de Historia Antigua, 5, 267 ss.

(29) Mangas, J.; Cortina, I.: "Nuevas urnas en forma de casa de Poza de la Sal (Burgos)", Memoria de Historia Antigua, 5, 273 ss.

(30) Indigenismo y romanización en el Conventus Asturum, Madrid, 1983, 165 ss.

(31) Astures en la época romana, Madrid, 1982, 302 SS.

(32) Avila romana, Avila, 1980, passim.

(33) "Arte, decoración, simbolismo e outros elementos da cultura material castrexa. Ensaio de sintesis", Estudos de Cultura castrexa e de historia antiga de Galicia, Compostela, 1983, 159 ss. 
de deidades, de héroes nacionales, o locales divinizados, de carácter apotropaico, o de espíritus protectores del lugar, de iconos funerarios, de estatuas honoríficas, funerarias o votivas a un dios de la guerra.

El hallazgo de dos esculturas in situ en el castro de Sanfins, no colocadas sobre túmulo, descarta la interpretación funeraria. Varias de estas esculturas han aparecido a la entrada del castro, por lo que el autor se inclina a pensar de que trata de un héroe, pero no de una divinidad guerrera. Serían estos guerreros símbolos de la fueza del castro, fundadores más o menos míticos, o defensores del castro.

28. G. López Monteagudo (34) ha realizado un catálogo de todas las esculturas de "verracos» habidos hasta 1976, fecha en que terminó este trabajo, dando procedencia, medidas, descripción y bibliografía de cada una de ellas. Incorpora algunos ejemplares inéditos y descarta otros después de comprobar su autenticidad. Después de proyectar geográficamente este tipo de esculturas en un mapa de la Península Ibérica, G. López Monteagudo, introduce todas las manifestaciones culturales que se producen en el área geográfica ocupada por las esculturas de "verracos»: arquitectura, cerámica, armas, fíbulas, orfebrería y metalurgia, pertenecientes a las fases "Cogotas I» y "Cogotas II" de la cultura de los Castros de la Meseta occidental. Se estudia, asimismo, los pueblos que se distribuyen en la antigüedad por esa zona, las lenguas, la organización social, la religión y las necrópolis.

Los "verracos" quedan encuadrados, por vez primera, dentro de un ambiente cultural que tiene sus raíces en el Bronce Final y que se prolonga con la conquista romana. Tras el estudio minucioso de los escasos hallazgos in situ de tales esculturas y del análisis de las inscripciones funerarias latinas, que algunas llevan grabadas sobre el costado, la autora llega a unas conclusiones en cuanto a cronología y significado de las mismas. El hallazgo más antiguo lo proporciona el castro de La Mesa de Miranda (Chamartín de la Sierra, Avila) a fines del siglo VI o comienzos del $\mathrm{V}$ a. C., pudiéndose fechar los más modernos en los siglos II y III d. C. por las inscripciones latinas, sugiriendo G. López Monteagudo que estas fechas tan bajas quizás pueden explicarse por la política romana de apoyar a los pueblos de la Península Ibérica que habían sufrido la expansión de los grupos celtibéricos, restituyéndoles en sus antiguos límites y revitalizando al mismo tiempo sus tradiciones indígenas, entre las que estarían las gentilidades y los verracos.

Por otra parte, el hallazgo de estas esculturas zoomorfas en relación con necrópolis o con sepulturas y las mismas inscripciones funerarias que algunos ejemplares ostentan, no dejan lugar a dudas acerca de su significado funerario, según $\mathrm{G}$. López Monteagudo. Esta hipótesis queda confirmada con el hallazgo de las esculturas de Martiherrero (Avila), que la autora incorpora en un trabajo posterior (35), las cuales aparecieron en relación con sepulturas de época romana. En este mismo trabajo, realizado seis años después con nuevos elementos de juicio, G. López Mon-

(34) Expansión de los "verracos" y caracteristicas de su cultura. Ed. de la Universidad Complutense de Madrid, 1983. Colección Tesis Doctorales, n. ${ }^{\circ} 124 / 83$.

(35) López Monteagudo, G.: "Las esculturas zoomorfas “célticas” de la Península Ibérica y sus paralelos polacos", $A E s p A, 55,1982,3$ ss. 
teagudo establece una posible relación de los "verracos» con un culto a un dios indígena que podría identificarse con Marte, marcando una conexión con las esculturas zoomorfas polacas de Wroclau, con recintos sagrados de tipo «céltico", con suouetaurilia, y todo ello dentro de un contexto de cultos solares - que la autora ya había intuido en el trabajo anterior - en relación con una divinidad guerrera y chtónica al mismo tiempo.

29. De Cabra (Córdoba), se ha publicado recientemente un ara, muy probablemente consagrada a Dominae Deavae, que parece ser un teónimo nuevo. Se trata de una deidad femenina acuática, o sea el Río de Cabra, aunque generalmente las personificaciones de los ríos son deidades masculinas en el Imperio Romano. Se trataría, como indica A. Stylow (36), de la primera deidad prerromana conocida de la Bética, con nombre de raigambre celta, tal como ocurre con el nombre del dios Neto del vecino Acci (Guadix). La romanización de la Bética, como recuerda este autor, fue rápida e intensa, y por lo tanto se perdió todo rasgo de la religiosidad tartésica y turdetana. Es significativo, como puntualiza A. O. Stylow, que sea precisamente la infiltración celta la que haya dejado alguna que otra huella.

30. J. M. Abascal (37) ha publicado toda la epigrafía de la provincia de Guadalajara, entre la que hay varios dioses indígenas: Arconi, Aside, Epona, Fapit...? Lugus, Reni.

31. Hemos publicado una larga síntesis de la religión indígena en época romana, bien ilustrada, y con toda la bibliografía fundamental en el tomo de la Historia de España. España Romana, Madrid, 1983, Editorial Espasa-Calpe, 261 y ss.

32. Está en prensa una addenda et corrigenda nuestra a las religiones indígenas hispanas en el Homenaje al prof. F. Rodríguez Adrados. Editorial Gredos, en el que se recogen las últimas aportaciones al tema (38), aparecidas en los últimos años.

33. Hemos publicado un libro sobre este tema en 1983, en el que intentamos reunir toda la bibliografía, las diferentes opiniones, abundantemente documentado. Lleva por título: Primitivas religiones ibéricas II, Religiones prerromanas, Madrid, donde exponemos nuestras opiniones actuales sobre el tema.

34. Hemos publicado una gran síntesis de la religión indígena hispana en $A N R W$ II, 1986, 164 y ss. Einheimische Religionen Hispaniens in der römischen Kaiserzeit, con una lista confeccionada por M. L. Albertos de todos los teónimos hispanos corregidos por la citada autora.

35. Sigue aumentando la lista de teónimos hispanos. A los ya conocidos hay que añadir los siguientes:

(36) “Inscripciones latinas del sur de la provincia de Córdoba», Gerión, 1, 1983, 295 ss.

(37) "Epigrafía romana de la provincia de Guadalajara», Wad-Al-Hayara, 10, 1983, 49 ss.

(38) Blázquez, J. M.: "Ultimas aportaciones a las religiones primitivas de Hispania», Homenaje a Antonio Tovar, Madrid, 1972, 81 ss.; idem, "Nuevos teónimos hispánicos (Addenda y Corrigenda)", CEG, 29, 1974-75, 23 ss.; idem, "Ultimas aportaciones a las religiones primitivas de Hispania", Estudios dedicados a Carlos Callejo Serrano, Cáceres, 1979, 1 ss. de la separada. idem, Imagen y mito. Estudios sobre religiones mediterráneas e ibéricas, Madrid, 1977; idem, Diccionario de las religiones prerromanas de Hispania, Madrid, 1975; idem, Religiones primitivas de Hispania. I. Fuentes literarias y epigráficas, Madrid, 1982; idem, "Die Mythologie der Althispanier, Götter und Mythen im Alten Europan, Wörterbuch der Mythologie. II, Stuttgart, 1973, 705 ss. 
En Longroiva (Meda) (39), en el Conventus Scallabitanus se ha hallado un ara consagrada a Bande Longobrico, u Oncobrico (fig. 4), que dice:

Q(uintus). IVLIVS/MONTA[NV]S / EQ(ues). LEG(ionis) VII (septimae) [G(eminae)] / F(elicis). BANDI. [L?]O/NOGOBRICV / V(otum). S(olvit). L(ibens).

$$
\mathrm{A}(\text { nimo). }
$$

36. En la villa de Freiria (Cascais), en el mismo conventus se halló una lápida consagrada a Triborunnis (40) (fig. 5). Dice así:

TRIBORVNNI / T(itus). CVRIATIVS / RVFINVS. / L(ibens). A(nimo). D(edit)

37. En la Sierra de Gata en el Conventus Emeritensis (41) ha aparecido una dedicatoria a Toga (fig. 6):

TOGAE / RVFVS / VEGETI / F(ilius). V(otum). L(ibens). A(nimo). S(olvit).

38. Un fragmento de ara a Endovollico (42) se halló en Juromenha en el Conventus Pacensis. Dice así:

\section{ENDOVOLLICO / SACRVM POS(uit) / T(itus) ANNIVS / VS. [ . . ] R [...] PATRV[?]}

39. En un árula votiva de Aguada de Cima (43) (fig. 7), se lee:

CVSEI. PAETA/[I?]CO BOVTOIVS / TVRAIANI[?] (filius) / A(nimo) L(ibens) $\mathrm{P}$ (osuit).

40. En Vendas de Cavernães se veneraba a Luruni (44) (fig. 8) según reza una inscripción:

LVRNI/SAC(rum). VAL(eria) / CATTIA/ A(nimo). L(ibens). V(otum). S(olvit).

41. En Furtado se recogió una ara dedicada a Collovese Caieloni Cosigo (45) (fig. 9):

\section{PVDENS / COMPETRI (filius) / ARAS EI/COLLOVESEI /}

\section{CATELONI C/OSIGO}

42. En una inscripción de Paranhos da Beira se lee: M(?). B(?). S(?). / IVNIA / FIRMINA / A(nimo). L(ibens). V(otum). S(olvit).

Las interpretaciones propuestas pueden ser:

a) $\mathrm{M}$ (arti) $\mathrm{B}$ (oro).

b) $\mathrm{M}($ ercurio $) \mathrm{B}(=$ epíteto $)$.

(39) Patricio Curado, F.: "Ara votiva de Longroiva (Meda) (Conventus Scallabitanus)", Ficheiro Epigráfico, 11,1985, n. $^{\circ} 44$.

(40) d'Encarnação, J.: “Ara votiva a Triborunnis», Ficheiro Epigráfico, 14, 1985, n. ${ }^{\circ} 59$.

(41) Figuerola, M. G.: "Inscripción a Toga en la Sierra de Gata (Conventus Emeritensis», Ficheiro Epigráfico, $12,1985, \mathrm{n} .^{\circ} 49$.

(42) Pinheiro, M. J.; Pinheiro, T. D.: «Fragmento de ara a Endovólico de Juromenha (Conventus Pacensis)", Ficheiro Epigráfico, 15, 1985, n. ${ }^{\circ} 64$.

(43) Carvalho, P.: "Arula votiva de Aguada de Cima", Ficheiro Epigráfico, 16, 1986, n. 70.

(44) da Sa Ferreira, A. I.: "Arula votiva de Vendas de Cavernaes", Ficheiro Epigráfico, 16, n. 71.

(45) Patricio Curado, F.: "Ara votiva de Furtado", Ficheiro Epigráfico, 17, 1986, n. 74. 


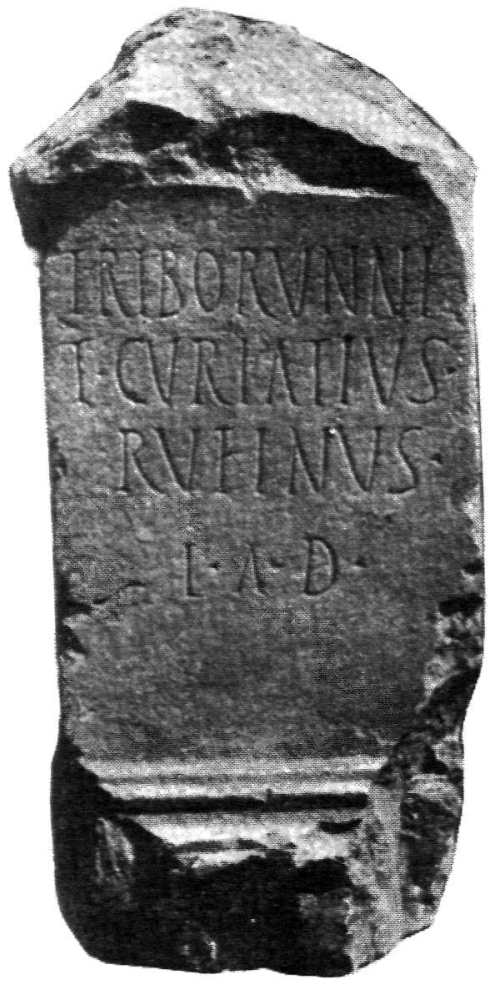

FIG. 5.-Ara de Triburunnis. Villa romana de Freiria, Cascais (según J. d'Encarnação).

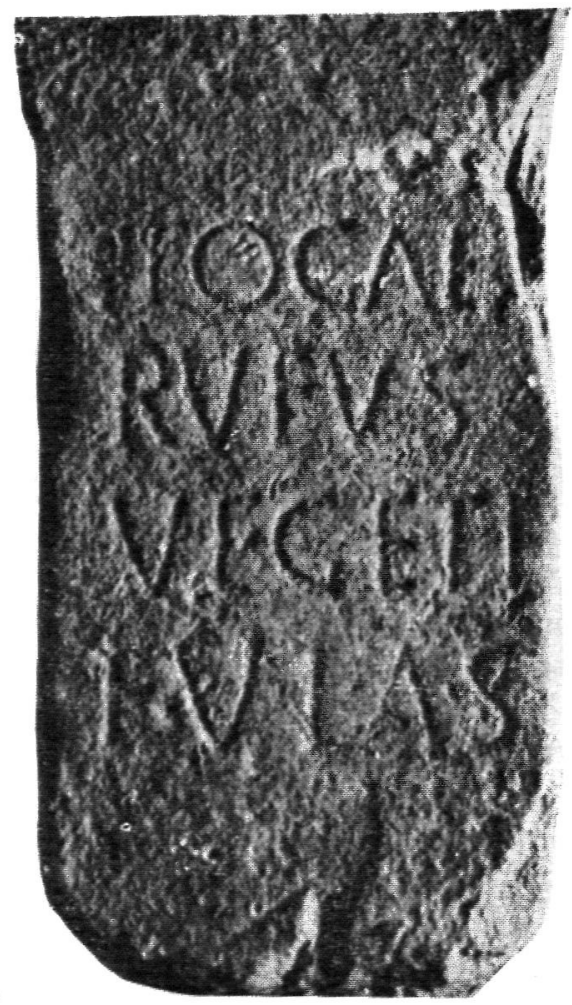




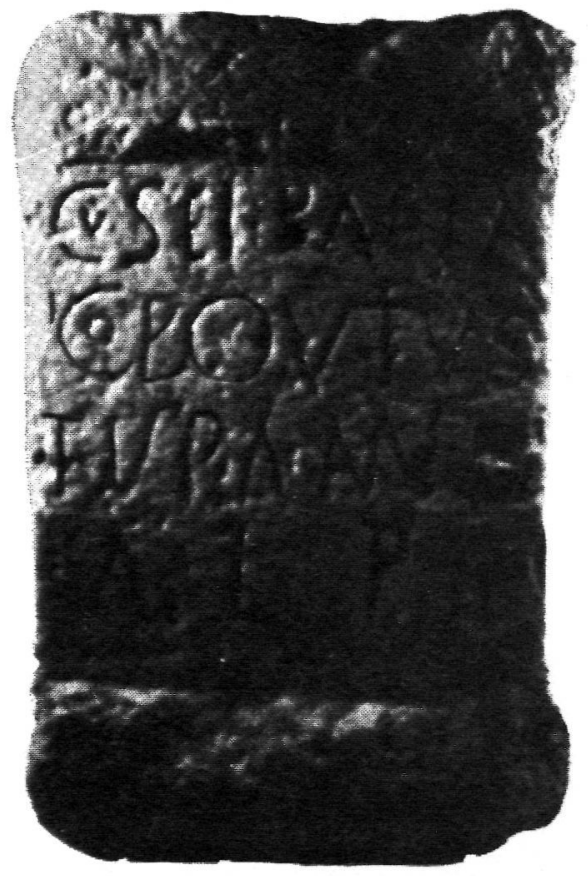

FIG. 7.-Ara de Cusei Paetaico.

Aguada de Cima

(según P. Carvalho).

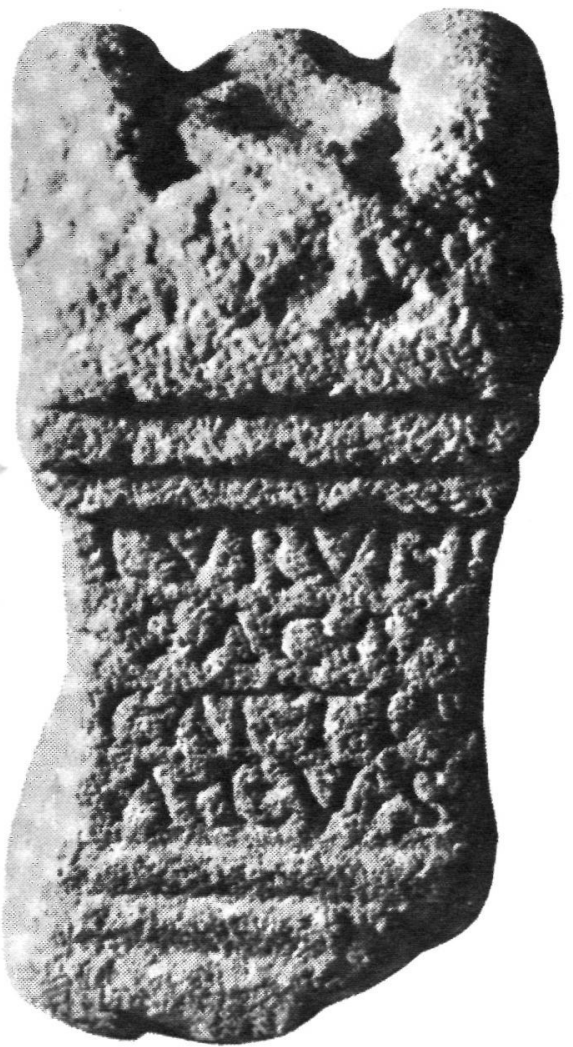


c) $\mathbf{M}$ (unidi) $\mathrm{B}$ (= epíteto).

d) $\mathrm{M}$ (atri) $\mathrm{B}$ (onae).

La letra es del siglo I (46).

43. En el santuario del Coll (Susqueda), se lee en una inscripción el nombre de Seitundo (47). La inscripción dice:

$$
\text { D(eo) SEI/TVND/O ARA(m) / VOTI/VAM. }
$$

En la cara b se lee: [C]AM/PAN/VS ET / MAX/IM(us).

44. A. Canto y C. Fernández Ochoa (48) han corregido la lectura de un teónimo, que se había publicado como antropónimo, hallado en el Castro de Moias (Asturias). Según la lectura corregida la inscripción dice:

\section{Cara A: TIIROLVSMASSN}

Cara B: IVS VIIRI . . .

$$
\text { [Dovi]tero L(ibens) V(otum) S(olvit) M(erito) / Ass(i)n/ius Veri(mus?) }
$$

45. J. Mangas (49) recoge en un reciente estudio sobre los dioses de la Asturica Augusta anterior a su cristianización a Deo Vacocaburio, Deo Vagodonnaego, y a Caraedudi, también estudiados por T. Mañanes en su Epigrafía y numismática de Astorga romana y su entorno, Salamanca, 1982, n. ${ }^{\circ} 1,108$ y 101.

46. J. Mangas y J. M. Solana (50) con objeto de estudiar la romanización de la Meseta Norte, recogen una serie de topónimos, como Iupiter Candamius, Lug / Lugus, Epona, Aquae Eleteses, Nymphae, Nimphae Fontis Ameucn (?), Matres, Matres Tendeiterae, Matres Monitucinae, Matres Brigaecae, Matres Gallaicae, Lattueriis, Ordaecis o Sordaecis, Deis Ovevimir, Lougestericus, Lugoves, Iupiter Solutorius, Ilurbeda, Cossua, Vurovius, Vaelicus o Velicus, Amparamo, Bana, Mentoviacus, Acpulsoius, Cabuniaeginus, Boiogene, Peicocama. Recogen estos autores las fuentes alusivas a la religión indígena referente a la Meseta Norte: Suetonio, S. Martín Dumiense, Estrabón y Plutarco.

47. Hemos estudiado recientemente la magia entre las poblaciones de la Hispania Antigua (51), donde se examina el tema en el período orientalizante, en las culturas turdetanas, ibérica, indoeuropea, y en la Hispania Romana, recogiendo los cánones de los concilios referentes a la magia o superstición.

48. R. Sanz (52) ha estudiado en dos trabajos recientes la pervivencia de la religión indígena en época tardorromana y visigoda.

(46) Patricio Curado, F.: “Ara votiva de Paranhos da Beira", Ficheiro Epigráfico, 17, n. 76.

(47) Mayer, M.; Roda, J.: "L'epigrafia romana a Cataluya, estat de la questió i darreres novetats», Fonaments, 5, 181 ss.

(48) "Epígrafe votivo a Dovitero, procedente del castro de Mohias (Asturias)", BIEA, 105, 1985, 483 ss.

(49) "Dioses y cultos en Asturias Augusta antes de su cristianización", Actas I Congreso Internacional. Astorga romana, Astorga, 1986, 69 ss. 83.

(50) "Romanización y germanización de la Meseta Norte», Historia de Castilla y León, 2, Valladolid, 1985,

(51) "Magia y religión entre los pueblos indígenas de la Hispania Antigua", Religión, superstición y magia en el Mundo Romano, Cádiz, 1985, 137 ss.

(52) "Persecución del paganismo y su proyección en la Península Ibérica», Homenaje a Agustín Diaz, Granada-Almería, 1985, 399 ss. Idem, "Adivinación y sociedad en la Hispania tardorromana y visigoda", Homenaje al prof. Montero Diaz. 


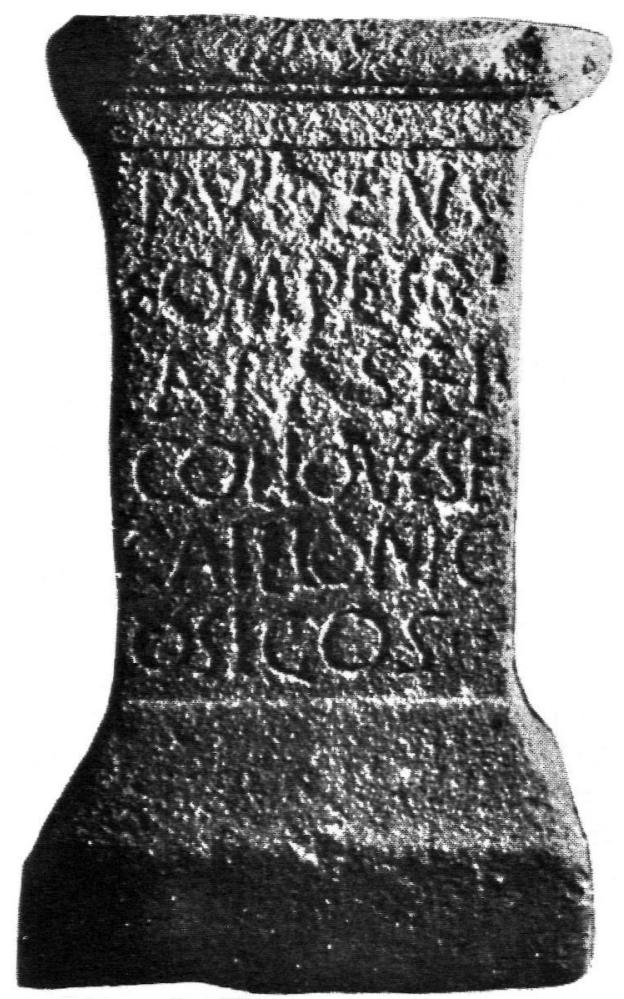

Fig. 9.-Ara de Eicollovesei Caieloni Cosigo. Furtado (según F. Patricio Curado).

49. J. d'Encarnação (53) en su estudio de las inscripciones del conventus pacensis analiza las inscripciones con teónimos indígenas, que son las siguientes: Ataecina, Carneus Calanticensis, deus Carneus Calanticensis, Dea Sancta Burrulobrigensis, Endovellicus, Ocrimira, Proserpina, Quanceius Tanngus, Sanctus Runesus.

50. A. Domínguez (54) explica el conocido texto de Estrabón (3.3.7.), sobre la religiosidad de los del norte hispánico, que relaciona con la escasez de teónimos al norte de la cordillera cántabra. Estudia el carácter del dios. Concluye que los habitantes de esta zona practicaban una especie de animismo. Analiza la interpretación de los autores griegos propuesta a este dios indígena.

(53) Inscriçōes romanas do Conventus Pacensis, Coimbra, 1984, n. ${ }^{\circ} 95,288$ (?); 287; 37; 410, 411, 412; 566, 800-805, 482-565; 610, 570, 574, 571-573; 641; 374; 611 respectivamente. Algunos de estos dioses eran desconocidos.

(54) "Algunas interpretaciones en torno a la religiosidad de los pueblos prerromanos del área cántabroastur", Homenaje a Agustín Díaz, 53 ss. 
51. F. Marco-Simón ha estudiado recientemente al dios Lug. Empieza su trabajo por un estudio general del dios Lug en la región celta para pasar a examinar a Lug en Hispania; antropónimos con este radical y su distribución en la Península Ibérica; topónimos; el santuario de Peñalba de Villastar, examinando detenidamente este templo, al aire libre, la significación de las oquedades excavadas en la roca, de carácter ritual; los sacrificios humanos en Hispania; las figuras del santuario turolense, ídolos, uno de ellos es una posible representación de Lug, y finalmente la inscripción con ofrendas en honor de Lug por parte de una cofradía religiosa.

52. En la Meseta Castellana siguen apareciendo nuevos teónimos, J. A. Abásolo (56) ha publicado una inscripción dedicada a Cesando:

CENSADO / COLLEGIVM / FABRORVM / V(otum) S(olvit) L(ibens) M(erito)

$$
\text { / } \mathrm{P}(\text { ropia }) \mathrm{p}(\text { ecunia }) \text { ? }
$$

Hallada en Lances (Burgos).

53. M. L. Albertos (57) revisa la significación de algunas divinidades lusitanas, como Salamati, que no sería un dios de carácter acuático, sino de la montaña, citado también en un ara de Ceclavín (CIL II, 794), donde se lee SALAMAIE, y en una segunda de Trijillo, (CIL II, 5279): SALAM/AC/NABI/ILVCIV/VSLM.

También estudia Arantius Ocelaecus, Arantia Ocelaeca, de una inscripción de Ferro, Covilha (Beira Baja), que dice: RVFVS. P/EICANI./ F. ARANT/IA OCELA/ECA. ET. A/RANTIO. OCELAECO/A.P. (o P.C), que relaciona con topónimos como Ocelum, Albocela o Albucela, Albocelum (?), Aebosocelum, Araocelum, Arcucelum, Balatucelum, Louciocelum, Tarbucelum, Sambrocola o Sambrucelum, Cusucelum (?).

54. J. L. Melena (58) estudia la epigrafía de Corregimiento, donde se recoge una serie de teónimos. El primero es Salamati, que se relaciona con una deidad de las montañas. Se publica la inscripción de Villamiel, donde se lee el teónimo y las otras dos citadas aras dedicadas al dios. Estas tres inscripciones dan pie al autor para recordar el culto al monte, como sedes deorum, mencionado por Apiano (Iber. 64), con motivo de las operaciones de Viriato, que es el Monte Afrodisio (App. Iber. 66). La Sierra de San Pedro, entre Cáceres y Badajoz, ha dado cuatro aras consagradas a Nabia. A continuación revisa el autor la distribución geográfica del culto a Salama. Otros teónimos examinados son los de Togae (San Martín de Trevejo), Ecussu (Villamiel), Deo Tetae, en la misma localidad, Ibero, también en San Martín de Trevejo, Palantico, en Perales del Puerto, y Arentio en Moraleja. Termina J. L. Melena su trabajo defendiendo el carácter orónimo del dios Salama y su posible interpretación romana. Salama acogía en su cumbre a la deidad celeste, agraria y guerrera, que sería finalmente suplantada por el padre de los dioses.

(55) "El dios céltico Lug y el santuario de Peñalba de Villastar", Estudios en Homenaje al Dr. Antonio Beltrán Martínez, Zaragoza, 731 ss.

(56) "Inscripciones romanas de las provincias de Segovia, Burgos y Palencia", AEspA, 58, 1985, 160 ss.

(57) "A propósito de algunas divinidades lusitanas", Symbolae Ludovico Mitxelena septuagenario oblatae, Vitoria, 1985,475 ss.

(58) "Salama, Jálama y la epigrafía del antiguo Corregimiento", Symbolae, 475 ss. 


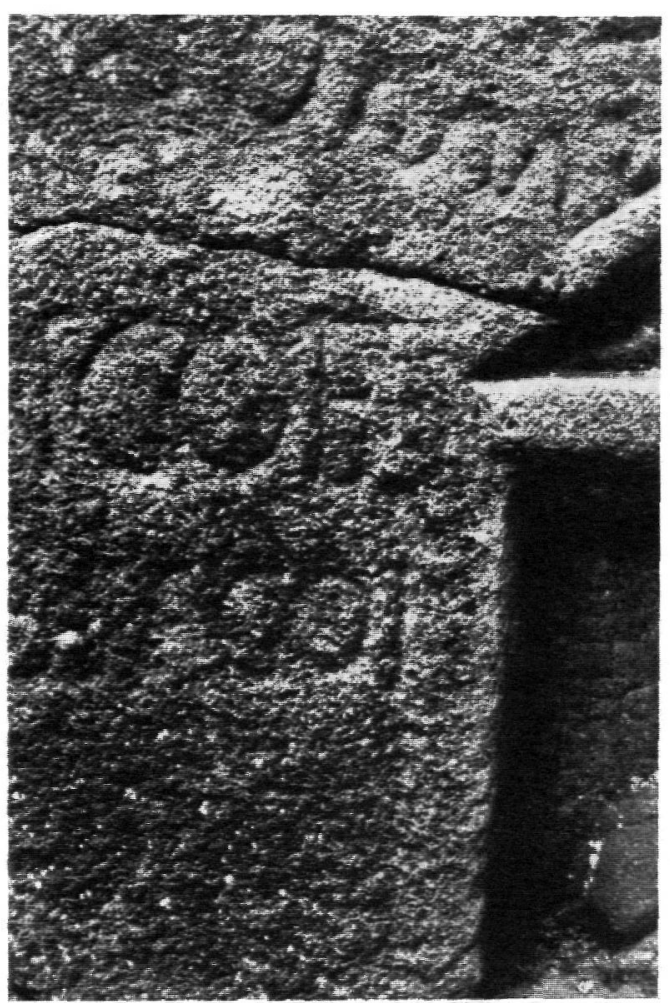

FIG. 10.-Ara de Tongoenabiagoi, Burgos (cortesía de G. Pereira).

55. G. Pereira (59) ha vuelto a tratar la inscripción del ídolo da fonte, Braga (fig. 10), quien propone la lectura de Tongoenabiagoi.

56. J. J. Sayas estudia los adivinos vascones y la Historia Augusta (60). Piensa en un influjo de Prudencio sobre el texto de la Historia Augusta.

57. A. Montenegro, J. A. Abásolo y J. D. Sacristán (61) han republicado los teónimos de la provincia de Burgos, que son: Iupiter Solutorius Edecus, Suttunius, este último no sería de origen indoeuropeo, sino preindoeuropeo; Aeiodaicino, con el mismo elemento compuesto de Aïoragatus (Peñalba de Castro, Burgos), y Aioadcino de Baños de Montemayor (Cáceres), Boiogena, compuesto sobre el étnico Boii, Brigiacae (Matres), Epona, Lugovibus, Monitucinae (Matres), Tendeiterae (Matres), Tullonius, Velon Atta y Vurovius.

(59) "La inscripción del ídolo de fonte, Braga", Symbolae, 531 ss.

(60) "Los adivinos vascones y la Historia Augusta", Symbolae, 593 ss.

(61) Montenegro, A.: Historia de Burgos, Burgos, 1985, 258 ss., 268 ss., 347 ss. 
58. J. C. Bermejo y otros autores (62) estudian una serie de mitos de la Hispania prerromana. Así examinan muy detenidamente la posible existencia de un nuevo mito turdetano (Diod. 33.7.5), dos pasajes míticos (un país devastado por la plaga, y el río del Olvido), la guerra de los bárbaros y Marte Cosus, los dioses de las montañas, las divinidades de las aguas, los dioses de los caminos, dieta real y dieta imaginaria y las serpientes gallegas.

59. A. Tovar con motivo de estudiar Las lenguas y pueblos de la Antigua Hispania. Lo que sabemos de nuestros antepasados protohistóricos, Vitoria, 1985, cita dos veces al dios Lug, de Celtiberia y de Galicia. Menciona el suovetaurilia de Cabeço das Fraguas y estudia filológicamente el mito de Habis.

60. M. I. Portela ha estudiado recientemente los Dioses Lares en la Hispania Romana, Lucentum 3, 1984, págs. 153-180, fijándose en el culto a los Lares en la religión romana; el culto a los Lares en la Hispania Romana; la documentación; los Lares tópicos y gentilicios que son 11: S. Juan de Baños (Iria), S. Pedro de Reádegos (Orense), Los Gozos (Orense), Aquae Flaviae (Chaves), Bracara Augusta (Braga), Freixo de Numâo (Portugal), Adaufé (Portugal), Conimbriga (Coimbra), Idanha-a-Velha (Portugal), Capera (Oliva, Cáceres), y Villamiel (Cáceres). Todos hallados en la costa atlántica norte, zona que asimiló poco la cultura romana. Son de procedencia indígena y por un fenómeno de sincretismo se identifican con los romanos. Se fechan en el siglo II. También estudia los Lares romanos y augustos, que son 30 repartidos por toda Hispania, y los Lares Viales, que son 23: Torres d'Oeste (Catoira), San Julián de Requeixo (Cesures), Santa Cruz de Fragoso, Caldas de Reyes, Brandomil (La Coruña), Castrofeito, Grava (Silleda), Guitiriz (dos), Lucus Augusti (Lugo), Neira de Jusá (Papín), Arcos (Pol, Lugo), Santianes de Tuña (Asturias), Chantada (Lugo), Santa María de Temes (Carballedo), S. Vicente de Castillós (Patón, Lugo), Santa Comba de Bande (Celanova), Cornoces (Orense), Santa María de Trives (Orense), Bracara Augusta (Braga), S. Xiao de Fontefría (Orense), S. Pelayo (Alava), Turiaso, Segóbriga (Cuenca). En ellos se da el mismo sicretismo que en los anteriores. El hecho de que, salvo tres, los restantes se localizan en el NO, indica que recubren deidades indígenas. Las estatuillas de Lares se localizan en Almazán (Soria), Pollentia (dos), Emerita Augusta, y Lora del Río (Sevilla).

Los colegios religiosos relacionados con el culto a los Lares están ausentes de Lusitania, Norte y Noroeste de Hispania, lo que probaría que no se relacionan con deidades indígenas.

61. F. Díez de Velasco ha estudiado los Balnearios y dioses de las aguas termales en Galicia romana, $A E s p A$ 58, 1985, págs. 69-98. Empieza este autor estudiando las divinidades de los balnearios de Gallaecia: el carácter de los dioses, la sacralidad de las aguas termales, las divinidades indígenas: Bormanico, Coventina, Edovio, los dioses que comienzan con Band-, las divinidades sincretísticas: Ninfas, Tutela, Fons; divinidades romanas y la cristianización y pervivencia del culto a las aguas en Gallaecia, para terminar con un inventario de las localidades termales de Gallaecia. 
62. J. d'Encarnação, Cascais no tempo dos romanos, Cascais, 1986, 9. Publica la inscripción votiva de Cascais, dedicadas a Triboruni, que dice:

TRIBORVNNI/T. CVRIATIVS/ RVFINVS/ L(ibens). A(nimo). D(edi), divinidad que debe ser quizás la misma o del mismo carácter que la Trebarunna de la inscripción de Cabeçọ das Fraguas, en Lusitania. 